\title{
Scavenging ratios of polycyclic aromatic compounds in rain and snow in the Athabasca oil sands region
}

\author{
L. Zhang ${ }^{1}$, I. Cheng ${ }^{2}$, D. Muir ${ }^{3}$, and J.-P. Charland ${ }^{4}$ \\ ${ }^{1}$ Air Quality Research Division, Science and Technology Branch, Environment Canada, 4905 Dufferin Street, Toronto, \\ Ontario, M3H 5T4, Canada \\ ${ }^{2}$ Independent Researcher, 5785 Yonge Street, Toronto, Ontario, M2M 4J2, Canada \\ ${ }^{3}$ Aquatic Contaminants Research Division, Science and Technology Branch, Environment Canada, 867 Lakeshore Road, \\ Burlington, Ontario, L7R 4A6, Canada \\ ${ }^{4}$ Air Quality Research Division, Science and Technology Branch, Environment Canada, 335 River Rd. S., \\ Ottawa, Ontario, K1A 0H3, Canada
}

Correspondence to: L. Zhang (leiming.zhang@ec.gc.ca)

Received: 26 May 2014 - Published in Atmos. Chem. Phys. Discuss.: 28 July 2014

Revised: 17 December 2014 - Accepted: 10 January 2015 - Published: 10 February 2015

\begin{abstract}
The Athabasca oil sands industry in northern Alberta, Canada, is a possible source of polycyclic aromatic compounds (PACs). Monitored PACs, including polycyclic aromatic hydrocarbons (PAHs), alkylated PAHs, and dibenzothiophenes (DBTs), in precipitation and in air at three nearsource sites in the Fort MacKay and Fort McMurray area during January 2011 to May 2012, were used to generate a database of scavenging ratios $\left(W_{\mathrm{t}}\right)$ for PACs scavenged by both snow and rain. Higher concentrations in precipitation and air were observed for alkylated PAHs and DBTs compared to the other PACs. The sums of the median precipitation concentrations over the period of data analyzed were $0.48 \mu \mathrm{g} \mathrm{L}^{-1}$ for the 18 PAHs, $3.38 \mu \mathrm{gL}^{-1}$ for the 20 alkylated PAHs, and $0.94 \mu \mathrm{gL}^{-1}$ for the 5 DBTs. The sums of the median air concentrations for parent PAHs, alkylated PAHs, and DBTs were 8.37, 67.26, and $11.83 \mathrm{ng} \mathrm{m}^{-3}$, respectively.

Median $W_{\mathrm{t}}$ over the measurement period were $6100-$ $1.1 \times 10^{6}$ from snow scavenging and $350-2.3 \times 10^{5}$ from rain scavenging depending on the PAC species. Median $W_{\mathrm{t}}$ for parent PAHs were within the range of those observed at other urban and suburban locations, but $W_{\mathrm{t}}$ for acenaphthylene in snow samples were 2-7 times higher compared to other urban and suburban locations. $W_{\mathrm{t}}$ for some individual snow and rain samples exceeded literature values by a factor of $10 . W_{\mathrm{t}}$ for benzo $(a)$ pyrene, $\operatorname{dibenz}(a, h)$ anthracene, and benzo $(g, h, i)$ perylene in snow samples had reached $10^{7}$, which is the maximum for PAH snow scavenging ratios re-
\end{abstract}

ported in the literature. From the analysis of data subsets, $W_{\mathrm{t}}$ for particulate-phase dominant PACs were 14-20 times greater than gas-phase dominant PACs in snow samples and 7-20 times greater than gas-phase dominant PACs in rain samples. $W_{\mathrm{t}}$ from snow scavenging were $\sim 9$ times greater than from rain scavenging for particulate-phase dominant PACs and 4-9.6 times greater than from rain scavenging for gas-phase dominant PACs. Gas-particle fractions of each PAC, particle size distributions of particulate-phase dominant PACs, and the Henry's law constant of gas-phase dominant PACs explained, to a large extent, the different $W_{\mathrm{t}}$ values among the different PACs and precipitation types. The trend in $W_{\mathrm{t}}$ with increasing alkyl substitutions may be attributed to their physico-chemical properties, such as octanol-air and particle partition coefficients and subcooled vapor pressure, which increases gas-particle partitioning and, subsequently, the particulate mass fraction. This study verified findings from a previous study of Wang et al. (2014) that suggested that snow scavenging is more efficient than rain scavenging of particles for equivalent precipitation amounts, and also provided new knowledge of the scavenging of gas-phase PACs and alkylated PACs by snow and rain. 


\section{Introduction}

Polycyclic aromatic compounds (PACs) are organic pollutants containing two or more benzene rings that are fused together and may contain additional ring structures. They are typically further classified into polycyclic aromatic hydrocarbons (PAHs) and dibenzothiophenes (DBTs), which contain sulfur. There are hundreds of PACs ranging from two-ring chemical structures to over six rings. Some PACs are substituted with functional groups, such as alkyl, amino, halogen and nitro groups (Boström et al., 2002). The chemical and physical properties, such as vapor pressure and water solubility, as well as the bioaccumulation potential and toxicity of PACs, vary with the structure of PACs, including the number of rings, molecular weight, and chemical substitutions (Ravindra et al., 2008; CCME, 2010). These properties play a role in atmospheric processes of PACs, their environmental fate, and impacts on animals and human health (Boström et al., 2002; Banger et al., 2010; Diggs et al., 2011; Muñoz and Albores, 2011). The probable human PAH carcinogens according to the USEPA are benz $(a)$ anthracene, benzo $(a)$ pyrene, benzo $(b)$ fluoranthene, benzo( $k)$ fluoranthene, chrysene, $\operatorname{dibenz}(a, h)$ anthracene, and indeno(1,2,3-cd)pyrene (ATSDR, 2008). In Canada, benzo $(a)$ pyrene, benzo $(b)$ fluoranthene, benzo $(j)$ fluoranthene, benzo $(k)$ fluoranthene, and indeno $(1,2,3-c d)$ pyrene are the PAHs that may constitute a danger to human life or health under the Canadian Environmental Protection Act (CCME, 2010). Abnormal physical and neurological development in infants has also been linked to prenatal exposure to PAHs (Perera et al., 2009). Less is known about the cancer and other health risks of alkylated PAHs because of the limited toxicity data (Baird et al., 2007; Wickliffe et al., 2014). Due to the potential toxic effects on animals and humans when exposed to PACs, it is necessary to quantify the deposition budget of PACs to terrestrial and aquatic ecosystems on local to regional scales.

The Athabasca oil sands industry in northern Alberta, Canada, is known to release significant amounts of PACs, among other pollutants (Jautzy et al., 2013; Parajulee and Wania, 2014). While PAH emissions are ubiquitous among combustion and industrial sources, alkylated PAHs and DBTs are specifically found in crude oil deposits including bitumen and emissions from bitumen upgrading facilities as well as wood combustion emissions. These pollutants have been observed in lakes, rivers, sediments, and snow cores in the Athabasca oil sands region (Kelly et al., 2009; Timoney and Lee, 2011; Jautzy et al., 2013; Kurek et al., 2013). One of the major pathways for PACs to enter terrestrial and aquatic environments is via wet deposition. In order to estimate wet deposition accurately, models need to account for the differences in scavenging efficiencies of gases and aerosols and various forms of precipitation (e.g., snow vs. rain) for in-cloud and below-cloud scavenging processes. Previous below-cloud aerosol scavenging studies found limited evidence that snow scavenging is likely more efficient than rain scavenging based on equivalent water content (Wang et al., 2014; Zhang et al., 2013). These findings can be verified with field measurements from the Athabasca oil sands region by determining scavenging ratios for PACs, including PAHs, alkylated PAHs, and DBTs. Furthermore, the investigation of precipitation scavenging efficiencies can now be extended to gaseous pollutants.

The scavenging ratio is a simplified measure for analyzing wet deposition and is defined as the ratio of the concentration of a chemical in precipitation to that in air (Cousins et al., 1999). In the literature, scavenging ratios were determined for radioactive particles, water vapor, sea salt, non-sea salt sulfate, nitrate, methanesulfonate, sodium, sulfur dioxide, particulate matter, carbonaceous aerosols, trace metals, PACs, and mercury (Barrie, 1985; Engelmann, 1971; Duce et al., 1991; Galloway et al., 1993; Guentzel et al., 1995; Franz and Eisenreich, 1998; Sakata and Asakura, 2007; He and Balasubramanian, 2009; Rothenberg et al., 2010; Hegg et al., 2011; Škrdlíková et al., 2011; Huang et al., 2013). Scavenging ratios were compared with previous values obtained from other locations to gain insight into some of the factors (e.g., precipitation characteristics, scavenging efficiency, and changes in source emissions) that may explain the discrepancies in scavenging ratio values (Rothenberg et al., 2010; Hegg et al., 2011). The relative scavenging efficiencies of PACs between rain and snow and between gas and particulate phases have also been compared based on their scavenging ratios (Franz and Eisenreich, 1998; Wania et al., 1999). Gas and particulate scavenging ratios for PACs have also been used to estimate the relative contributions or importance of gas and particle scavenging to total wet deposition (He and Balasubramanian, 2009; Škrdlíková et al., 2011). These studies have highlighted the facts that the knowledge of precipitation scavenging of PACs is still very limited and that more research is needed to understand the factors affecting wet deposition in order to improve model wet deposition estimates.

The objective of the study is to compare wet scavenging of PACs at the oil sands sites to other locations using scavenging ratios and to examine differences between snow and rain scavenging and between gas-phase and particulate-phase scavenging. This involves generating a database of scavenging ratios for PACs. The database could potentially be used in future wet deposition estimation using monitored surface air concentrations at locations where wet deposition is not monitored and will be detailed in a separate paper. 


\section{Methods}

\subsection{Data collection}

\subsubsection{Description of sampling sites}

PACs in precipitation and air were sampled at three sites in the Athabasca oil sands region in northern Alberta, Canada, where large deposits of bitumen are mined. The region is highly industrial because of the surface mining activities, oil sands production facilities, and industrial traffic. The three sites, AMS5 $\left(56^{\circ} 58^{\prime} 7.68^{\prime \prime} \mathrm{N}\right.$, $\left.111^{\circ} 28^{\prime} 55.2^{\prime \prime} \mathrm{W}\right), \operatorname{AMS} 11\left(57^{\circ} 1^{\prime} 36.73^{\prime \prime} \mathrm{N}, 111^{\circ} 30^{\prime} 2.7^{\prime \prime} \mathrm{W}\right)$ and AMS $13\left(57^{\circ} 8^{\prime} 57.12^{\prime \prime} \mathrm{N}, 111^{\circ} 38^{\prime} 32.64^{\prime \prime} \mathrm{W}\right)$, are air sampling sites from an existing monitoring network operated by the Wood Buffalo Environmental Association (WBEA) and are within $30 \mathrm{~km}$ from each other (Fig. 1). The sites are located along the Athabasca River near the Fort MacKay and Fort McMurray area and are near two upgraders, which process bitumen into synthetic crude oil. The two upgraders emit PAHs directly into the atmosphere and in tailings and waste rock disposals (Environment Canada, 2012).

\subsubsection{Sampling procedures}

Automated precipitation samplers (MIC Co., Thornhill, Ontario) were installed at the three sites. The wet-only samplers automatically open when rain or snow activates a sensor and contain a heated funnel and heated compartment for the XAD-2 resin column. Precipitation, including rain and snow, enters the heated funnel and through the XAD-2 column, where the dissolved and particulate PACs are collected, and then into a carboy to measure the precipitation volume. The wet deposition sampler does not include a filter unit for separating the particulate phase from the dissolved phase in precipitation. Therefore, both the dissolved and particulate PACs are collected on the XAD-2 column. The wet sampler is also equipped with a U-shaped siphon on the XAD-2 column outlet that maintains water in the column at all times, thus preventing air exchange. This is also minimized by covering the funnel where precipitation is collected except during precipitation events. Sampling of precipitation was conducted on a monthly schedule. The XAD-2 resin columns were shipped to the Canada Centre for Inland Waters (Environment Canada, Burlington, Ontario) for the determination of PACs in precipitation samples.

Simultaneously, air samples were collected for $24 \mathrm{~h} \mathrm{ev-}$ ery 6 days at the three sites using a modified high-volume air sampler. A vacuum pump draws in $700-1000 \mathrm{~m}^{3}$ of air through a Teflon-coated glass fiber filter (GFF) followed by a pair of polyurethane foam (PUF) plugs to collect both the particulate-bound and gas-phase PACs, respectively. Two PUF plugs were implemented because of potential breakthrough of low molecular weight PACs. Samples were wrapped in aluminum foil to reduce exposure to light

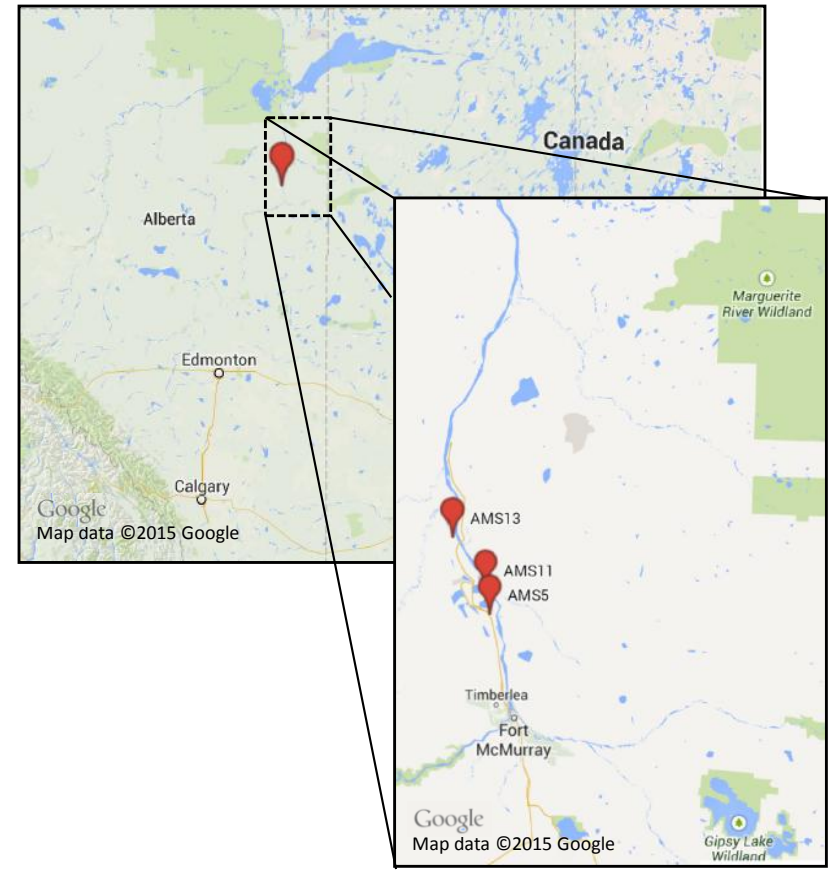

Figure 1. Precipitation and air monitoring sites in the Athabasca oil sands region.

and stored in a freezer at a temperature of $-10^{\circ} \mathrm{C}$ or less prior to analysis. Additional details on the sampling protocols are available in Harner et al. (2013). Average air temperatures corresponding to the collection of $24 \mathrm{~h}$ air samples were also recorded.

\subsubsection{Analytical procedures}

For the analysis of total PACs (dissolved and particulate phase) in precipitation, the XAD-2 resin was extracted in a clean room laboratory (HEPA and carbon filtered, positively pressured) by eluting first with acetone and then with dichloromethane (DCM). Recovery standards of deuterated PAH and DBT surrogates are added prior to XAD-2 column elution. The elution solvents are combined in a separatory funnel to separate the DCM phase. The aqueous phase that has been separated from the DCM phase is re-extracted with DCM. The DCM is back extracted with $3 \%$ sodium chloride solution and then dried by pouring through a column of sodium sulfate. The DCM is evaporated to a small volume and exchanged into cyclohexane. Prior to extraction of air samples, the GFFs and PUF plugs were spiked with a solution containing PAH and DBT surrogates. The GFF and PUF plug samples are then extracted by a Soxhlet apparatus for a period of 16 to $20 \mathrm{~h}$ with cyclohexane. The raw extract is then filtered through sodium sulfate and concentrated to a volume of 3 to $5 \mathrm{~mL}$ by rotary evaporation at $45^{\circ} \mathrm{C}$.

The cyclohexane extracts were further processed by the Air Quality Research Division (AQRD) laboratory (Ottawa, 
Ontario). The cyclohexane was fractionated on a silica column to separate aliphatic hydrocarbons (hexane elution) from PACs (elution with benzene). The column was eluted with $5 \mathrm{~mL}$ of hexane, followed by $5 \mathrm{~mL}$ of benzene, and the eluate is archived (aliphatic hydrocarbon fraction). The PACs were then eluted with two $5 \mathrm{~mL}$ aliquots of benzene into a calibrated centrifuge tube. The PAC fraction (benzene fraction) was concentrated to less than $0.9 \mathrm{ml}$ by UHP nitrogen. After addition of the $d_{10}$-fluoranthene internal standard, the purified sample extract is then brought to a known volume (typically $1.0 \mathrm{~mL}$ ) using benzene. The final purified extract was analyzed by gas chromatography (GC) low-resolution MS, which included an Agilent $6890 \mathrm{~N}$ or $7890 \mathrm{~A}$ GC interfaced directly to the Agilent 5973N, 5975 or 5975C mass selective detector. The samples were analyzed for PAHs, DBTs, and their alkyl derivatives. Some alkylated PAHs are reported as analyte groups because of co-elution, and the vast number of different congeners in the alkylated groups does not allow a more selective qualitative analysis. Alkylated PAHs have many structural isomers that share the same ion fragments, and most of them cannot be identified individually unless individual standards are available to compare retention times or retention indexes. There are many alkylated PAH standards available on the market, but they do not complete the full set of possible isomers that are found in complex samples like those from the oil sands. The analytical procedures follow Environment Canada AQRD protocol 3.03/4.6/M (2009) and Sun et al. (2006).

\subsubsection{Quality control and quality assurance}

Field blanks were collected for air and precipitation samples. The field blanks for the high-volume air samples, collected every 4-6 months at each of the three sites, consist of a clean GFF and a pair of PUF plugs that are placed in the sampler housing for the same duration as the samples without the vacuum pump turned on. For precipitation samples, field blanks were collected by exposing the XAD-2 columns to the atmosphere for 3 to $5 \mathrm{~min}$ at the site. One field blank was collected every month at a different site, which means that a set of blanks for all sites were collected in a 4 month period. Breakthrough tests were conducted on pairs of PUF plugs. The mass of naphthalene on the backup PUF was $59 \pm 2 \%$ of the total mass on the pair of PUF plugs for air sampling volumes ranging from 595 to $810 \mathrm{~m}^{3}$ at $25^{\circ} \mathrm{C}$. However, for most of the gas-phase dominant PACs (e.g., the sum of acenaphthylene, acenaphthene, fluorene, phenanthrene, anthracene, and 2-methylfluorene), the average and standard deviation of the percent breakthrough were only $15 \pm 7 \%$. Concentrations were blank corrected. Surrogate standards were added to each sample, method blanks, and control samples as part of quality assurance of analytical procedures in $\mathrm{AQRD}$ protocol 3.03/4.6/M (Environment Canada, 2009). Surrogate recovery percentages for parent PACs are shown in Table 1. Samples were corrected for surrogate recoveries if they were within
Table 1. Percent recoveries for deuterated PAC surrogates

\begin{tabular}{lrr}
\hline Deuterated PAC surrogates & Air & Precipitation \\
\hline $\mathrm{d}_{8}$-naphthalene & $68.6 \pm 9.9$ & $46.5 \pm 15.5$ \\
$\mathrm{~d}_{8}$-acenaphthylene & $73.1 \pm 17.6$ & $54.2 \pm 16.5$ \\
$\mathrm{~d}_{10}$-acenaphthene & $76.1 \pm 10.1$ & $55.0 \pm 17.3$ \\
$\mathrm{~d}_{10}$-fluorene & $90.5 \pm 20.0$ & $61.8 \pm 16.2$ \\
$\mathrm{~d}_{10}$-phenanthrene & $86.6 \pm 9.8$ & $71.3 \pm 19.5$ \\
$\mathrm{~d}_{10}$-anthracene & $80.4 \pm 12.9$ & $64.0 \pm 20.6$ \\
$\mathrm{~d}_{10}$-pyrene & $92.4 \pm 9.3$ & $77.8 \pm 20.6$ \\
$\mathrm{~d}_{12}$-benz $(a)$ anthracene & $102.3 \pm 13.9$ & $92.8 \pm 28.4$ \\
$\mathrm{~d}_{12}$-chrysene & $92.7 \pm 9.8$ & $77.2 \pm 17.8$ \\
$\mathrm{~d}_{12}$-benzo $(b)$ fluoranthene & $100.7 \pm 11.3$ & $90.6 \pm 18.4$ \\
$\mathrm{~d}_{12}$-benzo $(a)$ pyrene & $97.6 \pm 15.0$ & $81.3 \pm 26.9$ \\
$\mathrm{~d}_{12}$-perylene & $98.4 \pm 15.8$ & $80.3 \pm 21.6$ \\
$\mathrm{~d}_{12}$-indeno $(1,2,3$ - $c d$ )pyrene & $108.2 \pm 15.9$ & $92.3 \pm 25.3$ \\
$\mathrm{~d}_{14}$-dibenz $(a, h)$ anthracene & $105.8 \pm 11.6$ & $92.3 \pm 25.9$ \\
$\mathrm{~d}_{12}$-benzo $(g h i)$ perylene & $101.2 \pm 10.4$ & $87.2 \pm 22.8$ \\
$\mathrm{~d}_{8}$-dibenzothiophene & $56.7 \pm 20.1$ & $58.8 \pm 17.9$ \\
\hline
\end{tabular}

50-150\%. Parent PACs were used to calculate recovery percentages for alkylated PACs as well because deuterated alkyl PAC standards are not available from our laboratories. Samples with surrogate recoveries beyond this range were excluded from the calculation of scavenging ratios. Instrument detection limits and method detection limits for the target analytes in air samples ranged from 0.1 to $2 \mathrm{pg} \mu \mathrm{L}^{-1}$ injection and 4.0 to $839.7 \mathrm{ng} / \mathrm{sample}$, respectively. Method detection limits for the target analytes in precipitation samples were determined to be the same as the instrument detection limits, which ranged from 0.4 to $20 \mathrm{ng}$.

\subsection{Data analysis}

The scavenging of gaseous and particulate PACs by rain and snow has been studied using scavenging ratios, which is a simplified approach to examining the overall wet deposition process based only on the concentration of a chemical in precipitation to that in air.

Total scavenging ratios $\left(W_{\mathrm{t}}\right)$ were determined for 43 PACs at 3 oil sands monitoring sites (AMS5, AMS11, and AMS13) from precipitation and high-volume air samples. Air samples collected approximately every 6 days were averaged to correspond to the monthly precipitation samples collected between 2 January 2011 and 31 May 2012 (Tables S1 and S2 in the Supplement), which is the period of data analyzed in this study. Ideally, monthly average concentrations should be obtained from daily air concentrations in a month; however, due to the extensive costs, air sampling was only performed once every 6 days. The uncertainties from this averaging approach should not be larger than the uncertainties caused by other sources (e.g., measurements themselves and/or laboratory analysis). In addition to a lack of data to link individual precipitation samples to individual air samples, scavenging ratios were not determined for every precipitation event, be- 
cause the shorter timescale can lead to large variability in the scavenging ratios (Barrie, 1985; Galloway et al., 1993). For instance, the monthly average scavenging ratios can vary by a factor of $2-5$, whereas the variability increases to an order of magnitude for daily scavenging ratios (Galloway et al., 1993). In this study, the median scavenging ratios are based on the monthly scavenging ratios over the snowfall and rainfall periods (about 5-7 months) and should have smaller variability.

Only the air samples with PAC concentrations greater than MDL were averaged, similar to the data selection criteria used by Škrdlíková et al. (2011). The method detection limits (MDL) were established from the PAC air concentrations observed in field blanks: MDL $=$ average (field blanks) $+3 x$ standard deviation (field blanks). The total scavenging ratios were determined as follows (Škrdlíková et al., 2011):

$$
W_{\mathrm{t}}=\frac{C_{\mathrm{prec}}\left(\mathrm{ng} \mathrm{L}^{-1}\right) \times 1000\left(\mathrm{Lm}^{-3}\right)}{C_{\text {air }}\left(\mathrm{ng} \mathrm{m}^{-3}\right)}=W_{\mathrm{p}} \varphi+W_{\mathrm{g}}(1-\varphi),
$$

$W_{\mathrm{p}}=\frac{C_{\text {prec, } \mathrm{p}}}{C_{\mathrm{air}, \mathrm{p}}}$,

$W_{\mathrm{g}}=\frac{C_{\mathrm{prec}, \mathrm{d}}}{C_{\mathrm{air}, \mathrm{g}}}$.

$W_{\mathrm{t}}$ includes both the dissolved- and particulate-phase concentrations in precipitation and the gas- and particulate-phase concentrations in air, and may also be determined if the particulate scavenging ratio $\left(W_{\mathrm{p}}\right)$, gas scavenging ratio $\left(W_{\mathrm{g}}\right)$, and PAC particulate mass fraction in air $(\varphi)$ are known. $W_{\mathrm{p}}$ is determined from the particulate PAC concentration in precipitation $\left(C_{\text {prec,p }}\right)$ and the particulate concentration in air $\left(C_{\text {air,p }}\right)$, while $W_{\mathrm{g}}$ is based on the dissolved PAC concentration in precipitation $\left(C_{\text {prec,d }}\right)$ and the gas-phase concentration in air $\left(C_{\text {air,g }}\right)$.

The total scavenging ratios were categorized into snow and rain samples. Snow samples included precipitation sampling dates between 20 December and 1 April. Rain samples included the precipitation sampling dates between 30 April and 30 November. Total scavenging ratios were presented for snow and rain cases separately. The scavenging ratio calculation excluded low precipitation samples $(<1.5 \mathrm{~mm})$.

Using the particulate PAC fractions in air measured every sixth day at the AMS5 site, the PACs were categorized into predominantly gas-phase (i.e., $1-\varphi>0.7$ gas fraction) and particulate-phase $(\varphi>0.7$ particle fraction) PACs in order to analyze differences in the precipitation scavenging of gases and particles. There were 18 gas-phase PACs of lower molecular weight $\left(128.2-222.0 \mathrm{~g} \mathrm{~mol}^{-1}\right)$ and 15 particulate-phase PACs of higher molecular weight (228.3$284.4 \mathrm{~g} \mathrm{~mol}^{-1}$ ). The median particulate mass fractions of the gas-phase and particulate-phase PACs were 0.073 and 0.92 , respectively. Some of the PACs in Fig. 2 were not considered gas-phase dominant or particulate-phase domi-

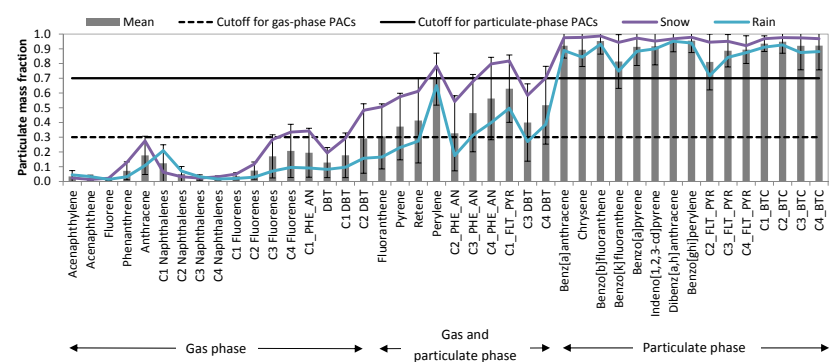

Figure 2. Average particulate mass fractions for gasphase and particulate-phase dominant PACs in snow and rain samples. PHE_AN $=$ phenanthrenes/anthracenes, DBT $=$ dibenzothiophene,$\quad$ FLT_PYR $=$ fluoranthenes/pyrenes $\mathrm{BTC}=\operatorname{benz}(a)$ anthracenes/triphenylenes/chrysenes.

nant PACs because of a small difference between the gas and particle fractions. They include fluoranthene, pyrene, retene, perylene, $\mathrm{C} 2 / \mathrm{C} 3 / \mathrm{C} 4-$ phenanthrene/anthracene, $\mathrm{C} 1$ fluoranthene/pyrene, and C3/C4-DBTs. Fig. 2 illustrates the mean and variability in the particulate mass fractions for all PACs. The variability could be due to vapor pressure of the PACs, air temperature, relative humidity, and chemical composition of particles because these parameters could affect gas-particle partitioning (Cousins et al., 1999; Hennigan et al., 2008). Most of the particulate mass fractions (i.e., mean \pm 1 standard deviation) for the gas-phase dominant parent PAHs in Fig. 2 were below 0.3, which is the criterion used to categorize gas-phase dominant PACs. For the particulatephase dominant parent PAHs, most of the particulate mass fraction measurements were above the cut-off criterion of 0.7. The particulate mass fractions measured at AMS5 are thought to be representative of those at AMS11 and AMS13 because the sites are within $30 \mathrm{~km}$ of each other and they are all near-source sites (near bitumen extraction and upgrading facilities). The temperatures ranged from -34.2 to $31.5^{\circ} \mathrm{C}$ at AMS5, -33.9 to $31.2^{\circ} \mathrm{C}$ at AMS11, and -39.2 to $32.8^{\circ} \mathrm{C}$ at AMS13, which are comparable. The temperatures at AMS5 and AMS11 were almost the same, while AMS13 was slightly colder than the other two sites based on the mean, median, and minimum temperatures (Table 2).

\section{Results and discussion}

\subsection{General statistics and comparison with literature}

Total scavenging ratios were determined for 43 PACs at the three sites from precipitation and air concentrations. The sums of the median precipitation and air concentrations for parent PAHs, alkylated PAHs, and DBTs at each of the three sites are shown in Fig. 3a and b. Among the sites, the highest precipitation concentrations were observed for alkylated PAHs, followed by DBTs and then parent PAHs. The sums of the median precipitation concentrations measured between 
Table 2. Statistics for air temperatures and precipitation amount at the AMS5, AMS11, and AMS13 sites in the Athabasca oil sands region. Hourly air temperatures were obtained from the Clean Air Strategic Alliance (CASA) Data Warehouse website.

\begin{tabular}{lrrrrrrrr}
\hline & \multicolumn{3}{c}{ Air temperature $\left({ }^{\circ} \mathrm{C}\right)$} & & \multicolumn{3}{c}{ Precipitation amount $(\mathrm{mm})$} \\
\cline { 2 - 3 } & AMS5 & AMS11 & AMS13 & & AMS5 & AMS11 & AMS13 \\
\hline Mean & 4.6 & 4.5 & 2.9 & & 17.9 & 14.3 & 18.2 \\
Median & 6.2 & 6.1 & 3.6 & & 12.0 & 8.3 & 13.1 \\
Standard deviation & 12.4 & 12.8 & 13.6 & & 17.5 & 15.1 & 21.0 \\
Min & -34.2 & -33.9 & -39.2 & & 0.2 & 0.0 & 1.4 \\
Max & 31.5 & 31.2 & 32.8 & & 75.5 & 62.5 & 93.8 \\
\hline
\end{tabular}

January 2011 and May 2012 were $0.48 \mu \mathrm{g} \mathrm{L}^{-1}$ for PAHs, $3.38 \mu \mathrm{g} \mathrm{L}^{-1}$ for alkylated PAHs, and $0.94 \mu \mathrm{g} \mathrm{L}^{-1}$ for DBTs. The PAHs that contributed the most to the total PAH concentration include chrysene, phenanthrene, and naphthalene. C4fluoranthene/pyrene contributed the most to the total alkylated PAHs, while C4-DBT contributed the most to the total DBTs. The summed concentrations in snow samples were 9 to 13 times greater than those in rain samples. A comparison of the summed concentrations of parent PAHs, alkylated PAHs, and DBTs in snow and rain samples are illustrated in Fig. 3c. The parent PAH concentrations in rainwater at the oil sands sites were higher than those at other suburban and rural locations (Franz and Eisenreich, 1998; Birgül et al., 2011, and references therein; Škrdlíková et al., 2011). The concentrations in snow were lower than those reported by Franz and Eisenreich (1998) and Wania et al. (1999) and at other urban locations (Birgül et al., 2011, and references therein). The different sampling methods for snow may explain the lower parent PAH concentrations compared to those from previous studies (Franz and Eisenreich, 1998; Wania et al., 1999). In previous studies, fresh snow was collected from the surface of snow packs, which could be exposed to both wet and dry deposition of PACs. In contrast, snow was collected in a wet deposition sampler in this study, which might result in lower PAC concentrations compared to literature values.

Air concentrations of alkylated PAHs were significantly higher than DBTs and parent PAHs at each of the three sites (Fig. 3b). Overall, the sums of the median air concentrations for parent PAHs, alkylated PAHs, and DBTs were 8.37, 67.26 , and $11.83 \mathrm{ng} \mathrm{m}^{-3}$, respectively. The air concentrations of parent PAHs at the oil sands sites were within the range of those reported in the literature (Franz and Eisenreich, 1998; Wania et al., 1999; He and Balasubramanian, 2009; Birgül et al., 2011, and references therein). Among the parent PAHs, naphthalene and phenanthrene concentrations in air were the highest. Elevated air concentrations were also observed for C3/C4-naphthalenes and C2/C3-DBTs. Unlike precipitation, the air concentrations of PACs associated with snow samples were only slightly higher than those associated with rain samples (Fig. 3c).

The median total scavenging ratios of parent PAHs for snow and rain scavenging were within the range of values reported in the literature (Fig. 4), which typically ranged from $10^{3}$ to $10^{7}$ for snow scavenging (Franz and Eisenreich, 1998; Wania et al., 1999) and from $10^{2}$ to $10^{6}$ for rain scavenging (He and Balasubramanian, 2009; Birgül et al., 2011; Škrdlíková et al., 2011). The comparison with literature values applies mainly to parent PAHs due to a lack of literature values for alkylated PAHs and DBTs. Two orders of magnitude difference in $W_{\mathrm{t}}$ were observed $\left(8.3 \times 10^{4}-1.2 \times 10^{6}\right)$ at a coastal-urban site in Singapore (He and Balasubramanian, 2009). The median total scavenging ratios for PACs also varied by 2 orders of magnitude $\left(4 \times 10^{2}-3.1 \times 10^{4}\right)$ at a suburban location in the Czech Republic (Škrdlíková et al., 2011). At an urban site in Turkey, the average total scavenging ratios for the gas and particle phases ranged from $8.52 \times 10^{5}$ to $8.97 \times 10^{5}$ (Birgül et al., 2011). Only the acenaphthylene snow scavenging ratios were $2-7$ times higher at the oil sands sites than the snow scavenging ratios at other locations.

When the individual snow and rain samples were analyzed (Table S3), the snow scavenging ratio for a particular snow sample exceeded the literature values by an order of magnitude for acenaphthylene (March 2011 at the AMS11 site), benzo $(b+k)$ fluoranthene (March 2011 at the AMS5 site), benzo(a)pyrene (April 2011 at the AMS5 site), dibenz $(a, h)$ anthracene (March 2011 at the AMS5 site), benzo $(g, h, i)$ perylene (April 2011 at the AMS5 site), and 2-methylphenanthrene (February 2011 at the AMS11 site). Scavenging ratios of $10^{7}$ were observed in some snow samples for benzo $(a)$ pyrene, $\operatorname{dibenz}(a, h)$ anthracene, and benzo $(g, h, i)$ perylene, which is the higher end for snow scavenging ratios reported in the literature. The scavenging ratio for a particular rain sample was an order of magnitude higher than literature values for naphthalene (May 2011 at the AMS11 site) and benzo(a)pyrene (December 2011 at the AMS13 site).

\subsection{Snow scavenging of gas-phase dominant and particulate-phase dominant PACs}

The scavenging ratios for snow samples were larger for particulate-phase than gas-phase PACs at the oil sands sites. The median total snow scavenging ratios were $8.0 \times 10^{5}$ for particulate-phase PAHs and $6.7 \times 10^{4}$ for gas-phase PAHs, 

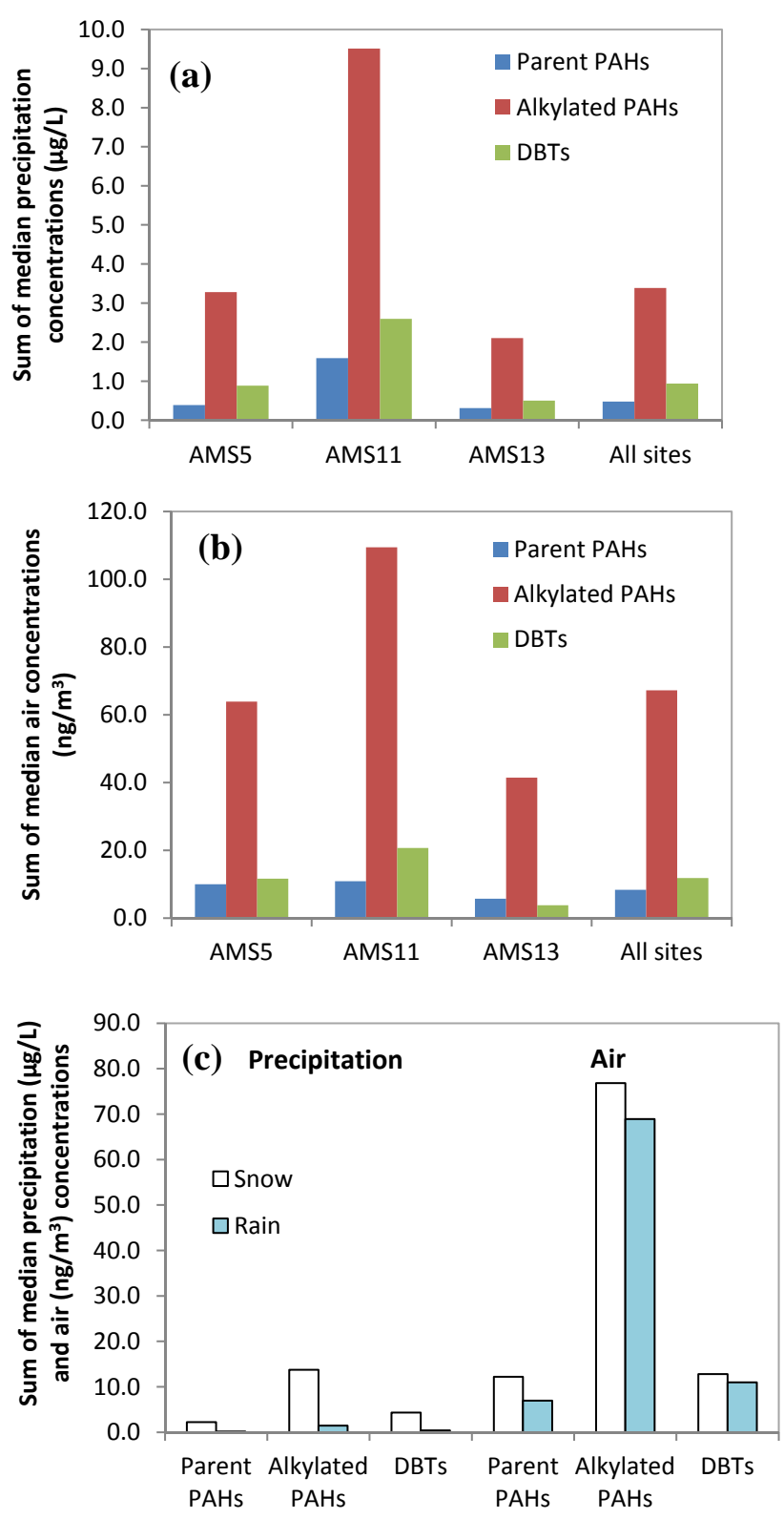

Figure 3. Sum of the median concentrations for parent PAHs, alkylated PAHs, and dibenzothiophenes (DBTs) in (a) precipitation and (b) air. Comparisons of the precipitation and air concentrations for snow and rain samples are shown in (c).

which were within those from previous studies (Fig. 4). These results were in agreement with the strong relationship between $\log W_{\mathrm{t}}$ and the particulate mass fraction of PACs in air $(\log \varphi)($ Franz and Eisenreich, 1998; He and Balasubramanian, 2009). According to the regression equation, larger $\varphi$ or particulate-phase PACs have higher total scavenging ratios than lower $\varphi$ (or gas-phase PACs). Particulate-phase PACs tend to have higher molecular weights and lower vapor pressure and volatility. Thus, they are more likely bound to particles. The order of magnitude higher scavenging ra-
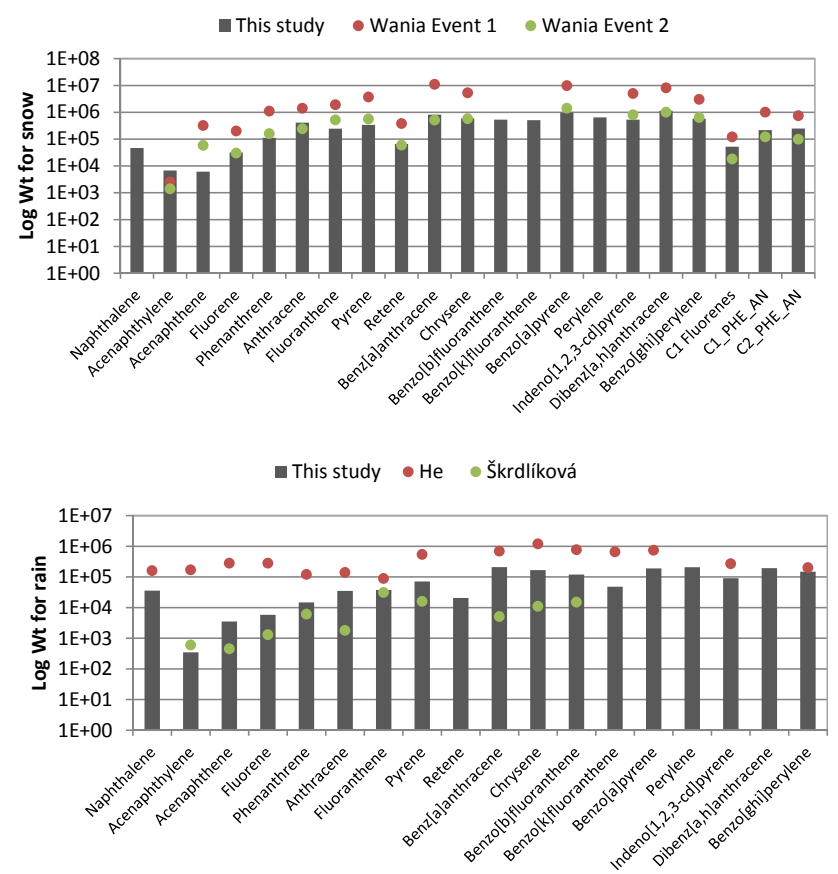

Figure 4. Comparison of total scavenging ratios $\left(W_{\mathrm{t}}\right)$ for snow and rain from this study and the literature (Wania et al., 1999; He and Balasubramanian, 2009; Škrdlíková et al., 2011). PHE_AN = phenanthrenes/anthracenes.

tio in the individual snow sample for the higher molecular weight PACs at the oil sands sites was likely due to the efficient scavenging of particles by snow. Furthermore, higher molecular weight PACs are typically associated with ultrafine and fine particles (He and Balasubramanian, 2009; Škrdlíková et al., 2011), which have larger scavenging coefficients than medium-size particles (Zhang et al., 2013; Wang et al., 2014).

Gas-phase dominant PACs, like acenaphthylene, have a lower molecular weight and higher vapor pressures and, therefore, are more volatile. However, a small mass fraction in particulate phase could increase its overall scavenging ratio $\left(W_{\mathrm{t}}\right)$ dramatically compared to the pure gas-phase scavenging ratio $\left(W_{\mathrm{g}}\right)$ due to the much higher value of $W_{\mathrm{p}}$ than $W_{\mathrm{g}}$ in the literature (Fig. 5a). Thus, this may be the reason for the higher snow scavenging ratio of acenaphthylene at the oil sands sites. The more volatile PACs will likely partition to existing particles of various sizes including large particles (Franz and Eisenreich, 1998; He and Balasubramanian, 2009; Škrdlíková et al., 2011). This typically results in a larger particulate scavenging ratio $\left(W_{\mathrm{p}}\right)$ for lower molecular weight PACs like acenaphthylene because large particles are scavenged more efficiently by precipitation (Ligocki et al., 1985). This is also supported by the higher semi-empirical snow scavenging coefficients for large particles compared to medium-size particles (Zhang et al., 2013; Wang et al., 2014). In a previous study, the gas scavenging ratio $\left(W_{\mathrm{g}}\right)$ of 


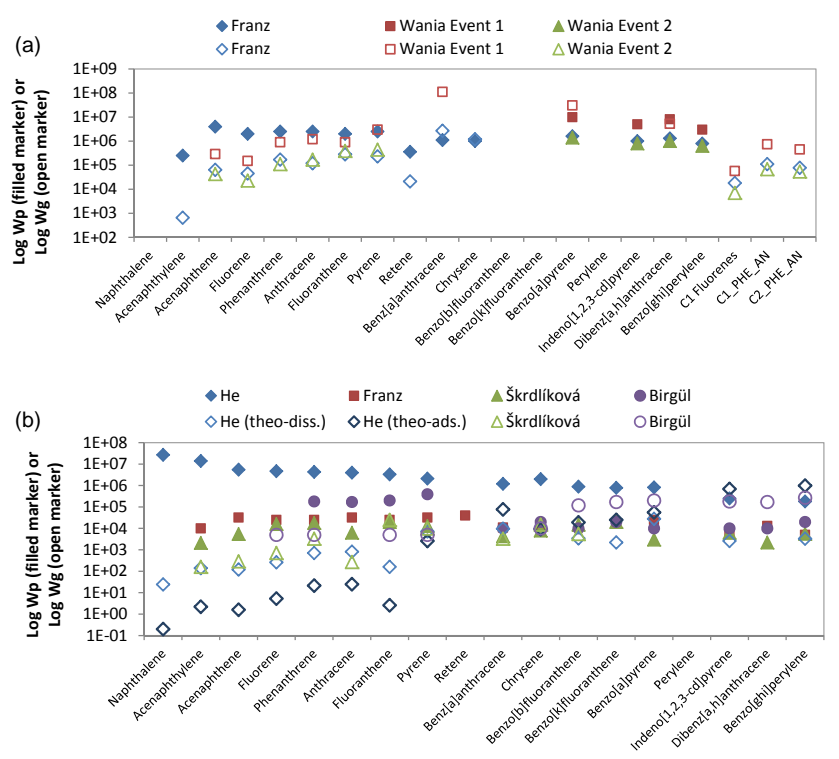

Figure 5. Particle and gas scavenging ratios for (a) snow and (b) rain obtained from the literature (Franz and Eisenreich, 1998; Wania et al., 1999; He and Balasubramanian, 2009; Birgül et al., 2011; Škrdlíková et al., 2011). PHE_AN = phenanthrenes/anthracenes.

acenaphthylene in snow was 385 times smaller than $W_{\mathrm{p}}$ in the literature, resulting in a larger particle scavenging contribution ( $74 \%$ ) to snow than gas scavenging (26\%) (Franz and Eisenreich, 1998). In this study, however, the concentration of acenaphthylene sorbed to particles in precipitation was not measured at the oil sands sites to estimate $W_{\mathrm{p}}$ and the contribution of particle scavenging of acenaphthylene to snow.

\subsection{Rain scavenging of gas-phase dominant and particulate-phase dominant PACs}

Similar to the snow scavenging results, the scavenging by rain was greater for particulate-phase than gas-phase PACs by an order of magnitude. The median $W_{\mathrm{t}}$ was $1.8 \times 10^{5}$ for particulate-phase PAHs and $1.1 \times 10^{4}$ for gas-phase PAHs. The scavenging ratios were within those reported in the literature, which ranged from 5100 to $1.2 \times 10^{6}$ for particulatephase PAHs and from 450 to $2.8 \times 10^{5}$ for gas-phase PAHs (Fig. 4). The larger $W_{\mathrm{t}}$ of particulate-phase PACs compared to gas-phase PACs was also consistent with the empirical relationship between $\log W_{\mathrm{t}}$ and the particulate mass fraction of PACs in air $(\log \varphi)$ (Franz and Eisenreich, 1998; He and Balasubramanian, 2009), similar to the result for snow.

Although the gas-phase PACs have a very low particulate mass fraction in air, Fig. 5b illustrates that the particulate scavenging ratios $\left(W_{\mathrm{p}}\right)$ can be 1-4 orders of magnitude larger than the theoretical and measured gas scavenging ratios $\left(W_{\mathrm{g}}\right)$ in the literature. Similar to snow scavenging, rain scavenging of particles containing gas-phase PACs contributed more than gas scavenging. For particulate-phase PACs, $W_{\mathrm{p}}$ and $W_{\mathrm{g}}$ for both rain and snow scavenging were more comparable in the literature (up to 1 order of magnitude difference, Fig. 5). Thus, the particle scavenging contribution to snow and rain will dominate the gas scavenging contribution because of the larger particle fraction. The data needed to determine $W_{\mathrm{p}}$ and $W_{\mathrm{g}}$ were not available at the oil sands sites to confirm literature findings and to estimate the relative gas and particle scavenging contributions to rain. In previous studies, the contributions of particle scavenging to rain were 99.41-99.99\% for gas-phase PACs and 86.35-99.58\% for particulate-phase PACs (He and Balasubramanian, 2009). In comparison, the contributions from gas scavenging were estimated to be up to $0.59 \%$ for gas-phase PACs and $13.7 \%$ for particulate-phase PACs (He and Balasubramanian, 2009). In a different study, the contributions of particle scavenging to rain by gas-phase PACs (17-59\%) were lower than by particulate-phase PACs (97-100 \%) (Škrdlíková et al., 2011). Higher volatility PACs, such as acenaphthylene and anthracene, are likely associated with larger particles, whereas non-volatile PACs tend to be associated with smaller particles (Škrdlíková et al., 2011). Based on the predicted scavenging coefficients for rain, the scavenging of very large particles $(>6 \mu \mathrm{m})$ is more efficient than that of fine and ultrafine particles (Wang et al., 2014).

The higher scavenging ratio for naphthalene in the individual rain sample at the oil sands sites compared to the literature must be attributed to gas scavenging, since $\varphi=0$ for naphthalene, resulting in $W_{\mathrm{t}}=W_{\mathrm{g}}$. Gas scavenging can occur by dissolution of gaseous PACs to the surface of raindrops. The gas scavenging ratio from the dissolution process $\left(W_{\mathrm{g}, \text { diss }}\right)$ depends on the temperature-corrected Henry's law constant, temperature, and the universal gas constant (Franz and Eisenreich, 1998). Another theory for gas scavenging is vapor adsorption to the surface of raindrops. This scavenging ratio $\left(W_{\mathrm{g}, \text { ads }}\right)$ can be determined from the air-water interface coefficient and diameters of raindrops (Simcik, 2004; He and Balasubramanian, 2009). However, the theoretical $W_{\mathrm{g}}$ for naphthalene reported in the literature was only 24.5 (Fig. 5b), which is $10^{5}$ times lower than the measured $W_{\mathrm{g}}$ in the individual rain sample at the oil sands sites. The differences between measured $W_{\mathrm{g}}$ at the oil sands site and theoretical $W_{\mathrm{g}}$ in the literature for naphthalene may be attributed to the different cloud and precipitation characteristics and are considered the major sources of uncertainties for precipitation scavenging (Galloway et al., 1993; Franz and Eisenreich, 1998).

\subsection{Comparison of PAC snow and rain scavenging processes}

Overall, the snow scavenging ratios of gas-phase and particulate-phase PACs were greater than those for rain scavenging. Median total scavenging ratios over the period of data analyzed were $6100-1.1 \times 10^{6}$ from snow scavenging and $350-2.3 \times 10^{5}$ from rain scavenging depending on the PACs. Since snowfall and rainfall intensities potentially affect precipitation scavenging, comparisons be- 
tween snow and rain scavenging should be conducted between snow and rain samples associated with similar precipitation intensity (Zhang et al., 2013; Wang et al., 2014). Based on selected snow and rain events with similar precipitation rates (snow: $11.6-11.8 \mathrm{~mm} \mathrm{month}^{-1}$; rain: $10.8-$ $12.3 \mathrm{~mm} \mathrm{month}^{-1}$ ), the median snow and rain scavenging ratios for gas-phase PACs were $1.2 \times 10^{5}$ and 8300 , respectively. The median snow scavenging ratios for particulatephase PACs were 40 times greater than those for rain for similar precipitation rates (snow: 11.6-11.8 $\mathrm{mm} \mathrm{month}^{-1}$; rain: $10.8-12.3 \mathrm{~mm} \mathrm{month}^{-1}$ ). For another set of snow and rain events (e.g, snow: 13.0-15.3 $\mathrm{mm} \mathrm{month}^{-1}$; rain: $13.2-$ $16.5 \mathrm{~mm} \mathrm{month}^{-1}$ ) at a different oil sands site, the median snow scavenging ratio for particulate-phase PACs was only 2 times larger than that for rain.

Potential explanations for the efficient snow scavenging of gas-phase PACs have been proposed in previous studies. Franz and Eisenreich (1998) had observed a stronger correlation between measured gas scavenging ratios and those calculated from gas scavenging by dissolution for snow events than for rain events. In this study, weak correlations were observed between the temperature-corrected Henry's law constant $\left(\mathrm{Pa} \mathrm{m}^{3} \mathrm{~mol}^{-1}\right)$ based on experimental data (Mackay et al., 2006) and theoretical values (Reid et al., 2013) and the total snow $(r=-0.36)$ and rain $(r=-0.20)$ scavenging ratios of gas-phase PACs, which suggest only minor influence of gas scavenging by dissolution. A moderate correlation coefficient of 0.56 was found between temperature-corrected water solubility of gas-phase PACs and total rain scavenging ratios; however, no relationship was found for total snow scavenging ratios. This furthermore implies that there is another mechanism involved in the gas scavenging of gas-phase PACs besides the dissolution process or that particle scavenging makes a larger contribution to the total wet deposition of gas-phase PACs.

Snow scavenging of gaseous PACs may be better modeled by surface or interfacial adsorption ( $\left.W_{\mathrm{g}, \text { ads }}\right)$. Measured $\log \left(W_{\mathrm{g}}\right)$ were strongly correlated with theoretical $\log \left(W_{\mathrm{g}, \text { ads }}\right)$ for snow events but not correlated in the rain events. This indicates that interfacial adsorption likely occurred in the snow events (Franz and Eisenreich, 1998). Wania et al. (1999) proposed that the scavenging of gas phase PACs likely occurred by adsorption to the air-ice interface because $W_{\mathrm{g}}$ was a strong function of both the partition coefficient for the air-ice interface and vapor pressure of the supercooled liquid. It suggests that snow scavenging of gas-phase PACs is potentially the dominant scavenging process for lower molecular weight or predominantly gasphase PACs (Wania et al., 1999). Compared to snow scavenging, rain scavenging of gas-phase PACs yielded much lower scavenging ratios in field and theoretical studies. For gas-phase PACs, $W_{\mathrm{g}}$ derived from field measurements ranged from 160 to 3300 , while the ranges for $W_{\mathrm{g}}$ due to dissolution and surface adsorption scavenging were only $24.3-710$ and $0.2-21.4$, respectively (Fig. 5b). Thus, the scavenging of gas- phase PACs by surface adsorption is evidently much lower for rain than for snow and may explain the difference in the snow and rain scavenging ratios at the oil sands sites.

Besides gas scavenging, gas-phase PACs typically have very large particulate scavenging ratios $\left(W_{\mathrm{p}}\right)$ because they are more likely to partition to particles. For snow events, $W_{\mathrm{p}}$ of gas-phase PACs can be 15-385 times larger than measured $W_{\mathrm{g}}$ in the literature. For rain events, $W_{\mathrm{p}}$ ranged from $5.5 \times 10^{3}$ to $2.7 \times 10^{7}$, while theoretical and measured $W_{\mathrm{g}}$ ranged from 25 to 3300 in the literature. Therefore, even though gas-phase PACs have a very low particulate mass fraction in air, the particle scavenging contribution to snow and rain can still be important, because $W_{\mathrm{p}}$ can be much greater than $W_{\mathrm{g}}$. Furthermore, the snow samples are associated with lower air temperatures, which may increase the partitioning of gas-phase PACs to the particulate phase (Pankow, 1991; Cousins et al., 1999). The average and SD of the air temperatures corresponding to snow and rain samples in this study were $-8.6 \pm 7.2$ and $8.9 \pm 8.6^{\circ} \mathrm{C}$, respectively, with an average temperature difference of $17.5^{\circ} \mathrm{C}$. As shown in Fig. 2, the average particulate mass fractions corresponding to snow samples were 2.5-4 times higher than those of rain samples for phenanthrene and anthracene. The combination of higher $W_{\mathrm{p}}$ and particulate mass fraction would yield higher total snow scavenging ratios. Particulate mass fractions for alkylated fluorenes, DBT, and C1/C2-DBTs during cold temperatures were also higher. Almost no differences in the particulate mass fractions between snow and rain samples were observed for the other parent gas-phase dominant PAHs.

Particle scavenging ratios for PACs in snow events were also observed to be larger than for rain events. Average $W_{\mathrm{p}}$ ranged from $10^{5}$ to $10^{6}$ for the snow events and from $10^{3}$ to $10^{4}$ for the rain event for particulate-phase PACs (Franz and Eisenreich, 1998). Snow is more efficient than rain at scavenging particles because of its larger surface area (Franz and Eisenreich, 1998). The relative scavenging efficiencies between snow and rain depend on particle sizes and precipitation intensity (Wang et al., 2014). For particulate-phase PACs that are likely associated with ultrafine and fine particles, the snow scavenging coefficient is predicted to be $\sim 10$ times larger than the rain scavenging coefficient at low precipitation rates (Wang et al., 2014). The temperature dependence of the particulate mass fractions can also explain the larger total scavenging ratios for snow than those for rain. The average particulate mass fractions associated with snow samples were $1-14 \%$ higher than in rain samples among the particulate-phase dominant PACs (Fig. 2). This is likely because at lower temperatures the vapor pressures of PACs in the particulate phase would be even lower, which causes them to remain bounded to particles. 


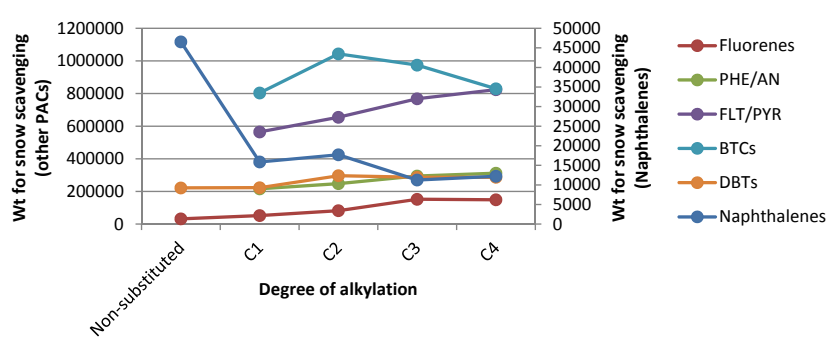

These physico-chemical properties are related to gas-particle partitioning (Pankow, 1994; Harner and Bidleman, 1998), which leads to a larger particulate mass fraction and, thus, higher $W_{\mathrm{t}}$. The large increase in $K_{\mathrm{oa}}$ from C3 to C4 fluorene corresponds to the large increase in $W_{\mathrm{t}} . \mathrm{p}_{L}^{0}$ is another physical property affecting gas-particle partitioning (Pankow, 1994), but is also related to snow scavenging of gas-phase PACs by interfacial adsorption. As $p_{L}^{0}$ decreases with alkyl substitutions, the interfacial adsorption coefficient $\left(K_{\mathrm{ia}}\right)$ increases (Franz and Eisenreich, 1998). This results in a higher contribution of gas scavenging by snow to the total scavenging ratio. The physico-chemical properties that have the most influence on the precipitation scavenging of alkylated fluoranthenes/pyrenes and benz $(a)$ anthracenes/triphenylenes/chrysenes are $\varphi$ and $K_{\mathrm{p}}$ because these are particulate-phase dominant PACs. Thus, particle scavenging contributions will dominate the total wet deposition of these PACs. $\varphi$ and $K_{\mathrm{p}}$ are predicted to increase with alkylation. The increase in $W_{\mathrm{t}}$ with alkyl substitutions is likely attributed to the increase in particulate mass fraction. For DBTs, the degree of alkylation increased with the rain $W_{\mathrm{t}}$, but did not have a large effect on snow $W_{\mathrm{t}}$. The trend in the rain $W_{\mathrm{t}}$ is consistent with the increase in $K_{\mathrm{oa}}, \varphi$, and $K_{\mathrm{p}}$, which are properties affecting gas-particle partitioning. The decrease in $p_{L}^{0}$ with increasing alkyl substitutions should result in an increase in gas scavenging by snow (due to adsorption on the air-ice interface); however, this was not reflected in the snow $W_{\mathrm{t}}$.

Alkylated naphthalenes, fluorenes, phenanthrenes / anthracenes, fluoranthenes / pyrenes, benz $(a)$ anthracenes / triphenylenes / chrysenes, and DBTs were measured at the three oil sands sites. For most of these PACs except for naphthalenes, total snow and rain scavenging ratios increased with the degree of alkylation (Fig. 6). These trends appeared to have some relationship with their physico-chemical properties, such as the Henry's law constant, the octanol-air partition coefficient $\left(K_{\mathrm{oa}}\right)$, subcooled vapor pressure $\left(p_{L}^{0}\right)$, water solubility, and the particulate mass fraction $(\varphi)$ and gasparticle partition coefficient $\left(K_{\mathrm{p}}\right)$, obtained from Reid et al. (2013). Snow and rain $W_{\mathrm{t}}$ for parent naphthalene were much higher than those of alkylated napthalenes. With an increase in alkylation, snow and rain $W_{\mathrm{t}}$ decreased. This trend is consistent with the increase in the Henry's law constant $\left(\mathrm{Pa} \mathrm{m}^{3} \mathrm{~mol}^{-1}\right.$ ), which leads to lower gas scavenging by dissolution (Franz and Eisenreich, 1998). This is further supported by the decrease in water solubility with increased alkyl substitutions. The large decrease in water solubility from parent naphthalene to $\mathrm{C} 1$ naphthalene is also reflected in the $W_{\mathrm{t}}$.

The other physico-chemical properties play a more prominent role in the precipitation scavenging of other alkylated PACs. For fluorenes and alkylated phenanthrenes/anthracenes, snow and rain $W_{\mathrm{t}}$ increased with alkylation. This trend is consistent with an increase in $K_{\mathrm{oa}}$, $\varphi$, and $K_{\mathrm{p}}$ as the number of alkyl substitutions increase.

\subsection{Uncertainties in snow and rain scavenging}

The ratio of the maximum to minimum $W_{\mathrm{t}}$ was used to estimate the uncertainties for snow and rain events with similar amounts of precipitation. The median $W_{\mathrm{t}}$ uncertainties among gas-phase PACs were a factor of 3.6 for snow scavenging and 1.9 for rain scavenging (Fig. 7a). The uncertainties from gas scavenging by snow can be very large, as shown in the estimated $W_{\mathrm{g}}$ for the interfacial adsorption process $\left(10^{3}\right.$ to $10^{10}$, Franz and Eisenreich, 1998). Field measurements of $W_{\mathrm{g}}$ can also be $0.43-20$ times greater than the theoretical $W_{\mathrm{g}}$ for snow scavenging (Franz and Eisenreich, 1998). There are several factors that can contribute to the uncertainties of measured $W_{\mathrm{g}}$, such as the higher than expected dissolved concentration of gas-phase PACs due to the presence of colloids in the filtrate (Franz and Eisenreich, 1998; He and Balasubramanian, 2009) and the repartitioning of dissolved PAHs to particles in snowmelt (Wania et al., 1999). The unfiltered submicron particles in the filtrate led to a measured $W_{\mathrm{g}}$ that was 100 times larger than the theoretical estimate (Poster and Baker, 1995a, b). The $W_{\mathrm{g}}$ estimated by Wania et al. (1999), which accounts for the repartitioning of dissolved PAHs to particles, were 2-5 times higher than those measured by Franz and Eisenreich (1998) for the same set of snow events. The adsorption of gas-phase PACs to the snow surface could also be enhanced by the presence of an organic 
layer (Franz and Eisenreich, 1998). Differences in the snow and rain properties are also contributing factors to the gas scavenging uncertainties. These data were not available in this study to assess their effects on the total scavenging ratio uncertainties.

Gas-phase PACs partition to particulate matter depending on temperature, which affects the particulate mass fraction and, subsequently, the total scavenging ratio. The snow events in Fig. 7a not only have similar precipitation amounts, but are also associated with similar air temperatures in order to minimize the temperature and gas-particle partitioning effects on the uncertainties of $W_{\mathrm{t}}$. Rain events associated with similar air temperatures were also used in Fig. 7a. Despite analyzing precipitation events with similar air temperatures, particulate mass fraction differed by factors of 1.6 and 1.5 (median among gas-phase PACs) for the snow and rain events, respectively. This may be due to other factors affecting the particle partitioning of gas-phase PACs (e.g., aerosol water content and chemical composition). When precipitation events with equivalent precipitation amounts but different air temperatures were examined, uncertainties in the total scavenging ratio increased (Fig. 7b). The median $W_{\mathrm{t}}$ uncertainties among gas-phase PACs rose to factors of 6.6 for snow events and 2.5 for rain events (Fig. 7a and b). This temperature effect on the uncertainties of the $W_{\mathrm{t}}$ is also supported by the larger difference in the particulate mass fraction.

The uncertainties in snow scavenging of particulate-phase PACs were larger than those for rain scavenging as shown in the range of scavenging ratios for snow and rain events with similar precipitation rates (Fig. 7c). The $W_{\mathrm{t}}$ uncertainties for snow and rain events were up to 10 and 7.7 , respectively, which were within the range of semi-empirical scavenging coefficients. For small particles $(<0.01 \mu \mathrm{m})$ that particulatephase PACs are typically bound to, Zhang et al. (2013) predicted that the ranges of scavenging coefficients are up to 2 orders of magnitude for snow and 1 order of magnitude for rain. Measurements are needed to confirm the particle size distribution of particulate-phase PACs because scavenging coefficient uncertainties for medium-size particles are predicted to be a factor of at least 10 larger than small and large particles (Zhang et al., 2013). Aside from particle sizes, the variability and uncertainties in the scavenging ratios could be due to the properties of snow and raindrops, such as snow shape and size of raindrops (Zhang et al., 2013). For example, in snow, the porosity of snowflakes and dendrites is considered effective for capturing small particles while allowing air to pass through (Franz and Eisenreich, 1998).

\subsection{Limitations and uncertainties of scavenging ratios}

As discussed in the last section, particle size distribution and snow and rain characteristics may contribute to the uncertainties in precipitation scavenging of PACs. The scavenging ratio parameter itself also has limitations and uncertainties due to the oversimplification of the precipitation scavenging
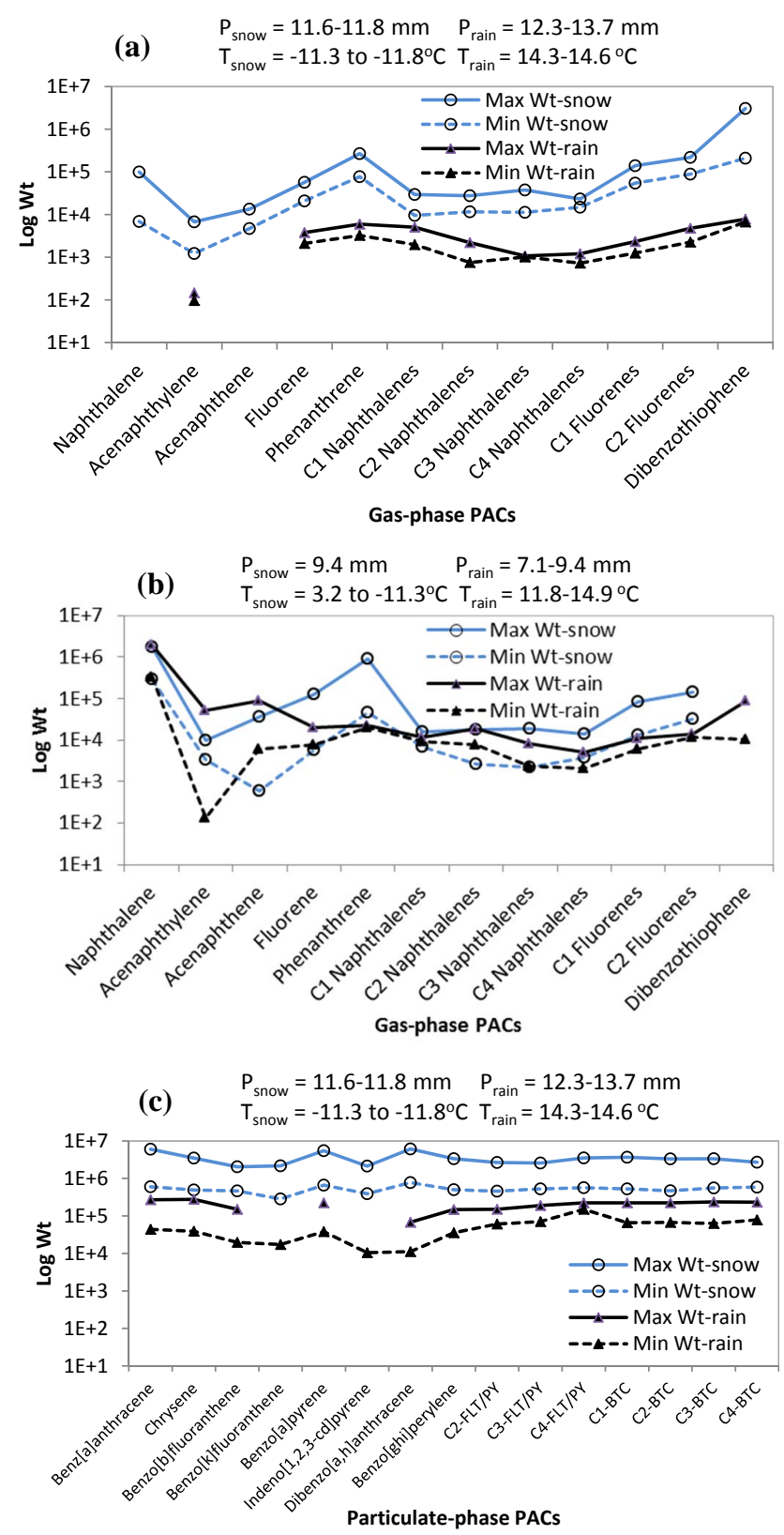

Figure 7. Range of total scavenging ratios $\left(W_{\mathrm{t}}\right)$ in snow and rain samples with (a) similar precipitation rates and air temperatures, (b) similar precipitation rates but different air temperatures, and (c) same as (a) but for particulate PACs. Note the use of the $\log$ scale for $W_{\mathrm{t}}$, which indicates that the range of $W_{\mathrm{t}}$ for snow is much larger than what is shown on the graph. $P=$ monthly precipitation; $T=$ air temperature. FLT/PY = fluoranthene/pyrene; $\mathrm{BTC}=\operatorname{benz}(a)$ anthracene/triphenylene/chrysene.

process. The large variability in the total scavenging ratios (e.g., a 4-5 order of magnitude range for PACs) may be attributed to numerous factors, such as particle size distribution, droplet sizes, cloud and precipitation type, and air mass trajectories (Duce et al., 1991; Galloway et al., 1993), which 
were not determined at the oil sands sites. To minimize variability, an average of a number of scavenging ratios should be determined over a longer time period instead of individual precipitation events (Duce et al., 1991; Galloway et al., 1993). In this study, the majority of the results were based on the median scavenging ratios from at least $14-15$ monthly snow and rain samples. The scavenging ratio concept also assumes that the air concentrations measured near the surface are representative of the concentrations in the cloud, where in-cloud scavenging may occur.

\section{Conclusions}

A database of scavenging ratios was developed for the 43 PACs monitored in air and precipitation samples in the Athabasca oil sands region. Overall, the median total scavenging ratios of most PACs, except for acenaphthylene, were within the range of scavenging ratios reported in the literature. Total scavenging ratios for some individual snow and rain samples exceeded literature values by a factor of 10. In some cases, snow scavenging ratios of $10^{7}$ were observed for benzo( $(a)$ pyrene, $\operatorname{dibenz}(a, h)$ anthracene, and benzo $(g, h, i)$ perylene, which is considered the upper limit for PAH scavenging ratios reported in the literature. The large range in scavenging ratios associated with samples of similar precipitation amounts implies the large natural variability and/or uncertainties in precipitation scavenging processes. Total snow and rain scavenging ratios increased with the number of alkyl substitutions for some PACs, which were consistent with the trends in their physico-chemical properties, such as subcooled vapor pressure and octanol-air and particle partition coefficients. The Henry's law constant and water solubility might play a role in the decrease in snow and rain scavenging ratios for naphthalene with increased alkyl substitutions.

The database of scavenging ratios was also separated into subgroups to investigate the relative importance of gas and particle scavenging by snow and rain. It was found that snow scavenging is around 10 times more efficient (in terms of the scavenging ratio values) than rain scavenging for both particulate-phase dominant and gas-phase dominant PACs. It was also found that scavenging of particulate-phase dominant PACs is 5 to 10 times more efficient than scavenging of gas-phase dominant PACs under both rain and snow conditions. These findings suggest that snow scavenging of particulate-phase PACs should contribute significantly to the total wet deposition of PACs in this region.

The database of PAC scavenging ratios (Table S3) could be used in future studies to predict the wet deposition flux at passive air monitoring sites in the Athabasca oil sands region. The total wet deposition flux is defined as the product of the total scavenging ratio, total air concentration, and precipitation rate (Duce et al., 1991; Sakata and Asakura, 2007). Although the uncertainties can be large because the factors affecting precipitation scavenging can vary with location, it may be a reasonable approach to provide a first-order estimation of wet deposition using the scavenging ratio concept. The detailed deposition budget of all the monitored PACs at the passive air monitoring sites will be investigated in a separate study.

\section{The Supplement related to this article is available online at doi:10.5194/acp-15-1421-2015-supplement.}

Acknowledgements. This study is supported by the Joint CanadaAlberta Implementation Plan for Oil Sands Monitoring. The authors acknowledge several colleagues at Environment Canada, Carlos Manzano, Jasmin Schuster, Tom Harner, and May Siu, for the helpful information on the precipitation and air data sets used in this publication, and field and lab technicians who have contributed to the data sets.

Edited by: A. Bertram

\section{References}

ATSDR: Polycyclic aromatic hydrocarbons (PAH): What health effects are associated with PAH exposure?, available at: http: //www.atsdr.cdc.gov/csem/csem.asp?csem=13\&po=11 (last access: 3 February 2015), 2008.

Baird, S. J., Bailey, E. A., and Vorhees, D. J.: Evaluating human risk from exposure to alkylated PAHs in an aquatic system, Hum. Ecol. Risk Assess., 13, 322-338, 2007.

Banger, K., Toor, G. S., Chirenje, T., and Ma, L.: Polycyclic aromatic hydrocarbons in urban soils of different land uses in Miami, Florida, Soil Sediment Contam., 19, 231-243, 2010.

Barrie, L. A.: Atmospheric particles: Their physical and chemical characteristics and deposition processes relevant to the chemical composition of glaciers, Ann. Glaciol., 7, 100-108, 1985.

Birgül, A., Tasdemir, Y., and Cindoruk, S. S.: Atmospheric wet and dry deposition of polycyclic aromatic hydrocarbons (PACs) determined using a modified sampler, Atmos. Res., 101, 341-353, 2011.

Boström, C. E., Gerde, P., Hanberg, A., Jernström, B., Johansson, C., Kyrklund, T., Rannug, A., Törnqvist, M., Victorin, K., and Westerholm, R.: Cancer risk assessment, indicators, and guidelines for polycyclic aromatic hydrocarbons in the ambient air, Environ. Health Perspect., 110, 451-488, 2002.

CASA - Clean Air Strategic Alliance: Data Warehouse, available at: http://www.casadata.org/(last access: 3 February 2015

CCME - Canadian Council of Ministers of the Environment: Canadian Soil Quality Guidelines for Carcinogenic and Other Polycyclic Aromatic Hydrocarbons (Environmental and Human Health Effects), Scientific Criteria Document (revised), 216 pp., 2010.

Cousins, I. T., Beck, A. J., and Jones, K. C.: A review of the processes involved in the exchange of semi-volatile organic compounds (SVOC) across the air-soil interface, Sci. Total Environ., 228, 5-24, 1999. 
Diggs, D. L., Huderson, A. C., Harris, K. L., Myers, J. N., Banks, L. D., Rekhadevi, P. V., Niaz, M. S., and Ramesh, A.: Polycyclic aromatic hydrocarbons and digestive tract cancers: a perspective, J. Environ. Sci. Health C, 29, 324-357, 2011.

Duce, R. A., Liss, P. S., Merrill, J. T., Atlas, E. L., Buat-Menard, P., Hicks, B. B., Miller, J. M., Prospero, J. M., Arimoto, R., Church, J. M., Ellis, W., Galloway, J. N., Hansen, L., Jickells, T. D., Knap, A. H., Reinhardt, K. H., Schneider, B., Soudine, A., Tokos, J. J., Tsunogai, S., Wollast, R., and Zhou, M.: The atmospheric input of trace species to the world ocean, Global Biogeochem. Cy., 5, 193-259, 1991

Engelmann, R. J.: Scavenging prediction using ratios of concentrations in air and precipitation, J. Appl. Meteor., 10, 493-497, 1971.

Environment Canada: Analytical Method for the Determination of PAH in Ambient Air Samples, Method No: 3.03/4.6/M, Air Quality Research Division (AQRD)/Division de la recherche en qualité de l'air, Analysis and Air Quality Section/Section des analyses et de la qualité de l'air, 335 River Rd., Ottawa, ON K1A 0H3, Canada, 2009.

Environment Canada: National Pollutant Release Inventory, available at: http://www.ec.gc.ca/inrp-npri/default.asp?lang=En\&n= 4A577BB9-1 (last access: 13 May 2014), 2012.

Franz, T. P. and Eisenreich, S. J.: Snow scavenging of polychlorinated biphenyls and polycyclic aromatic hydrocarbons in Minnesota, Environ. Sci. Technol., 32, 1771-1778, 1998.

Galloway, J. N., Savoie, D. L., Keene, W. C., and Prospero, J. M.: The temporal and spatial variability of the scavenging ratios for NSS sulfate, nitrate, methanesulfonate and sodium in the atmosphere over the North Atlantic ocean, Atmos. Environ., 27A, 235-250, 1993.

Guentzel, J. L., Landing, W. M., Gill, G. A., and Pollman, C. D.: Atmospheric deposition of mercury in Florida: the FAMS project (1992-1994), Water Air Soil Pollut., 80, 393-402, 1995.

Harner, T. and Bidleman, T. F.: Octanol-air partition coefficient for describing particle/gas partitioning of aromatic compounds in urban air, Environ. Sci. Technol., 32, 1494-1502, 1998.

Harner, T., Su, K., Genualdi, S., Karpowicz, J., Ahrens, L., Mihele, C., Schuster, J., Charland, J.-P., and Narayan, J.: Calibration and application of PUF disk passive air samplers for tracking polycyclic aromatic compounds (PACs), Atmos. Environ., 75, 123 128,2013

He, J. and Balasubramanian, R.: A study of precipitation scavenging of semivolatile organic compounds in a tropical area, J. Geophys. Res., 114, D12201, doi:10.1029/2008JD011685, 2009.

Hegg, D. A., Clarke, A. D., Doherty, S. J., and Ström, J.: Measurements of black carbon aerosol washout ratio on Svalbard, Tellus B, 63, 891-900, 2011.

Hennigan, C. J., Bergin, M. H., Dibb, J. E., and Weber, R. J.: Enhanced secondary organic aerosol formation due to water uptake by fine particles, Geophys. Res. Lett., 35, L18801, doi:10.1029/2008GL035046, 2008.

Huang, J., Chang, F. C., Wang, S., Han, Y. J., Castro, M., Miller, E., and Holsen, T. M.: Mercury wet deposition in the eastern United States: characteristics and scavenging ratios, Environ. Sci. Process. Impacts, 15, 2321-2328, 2013.

Jautzy, J., Ahad, J. M., Gobeil, C., and Savard, M. M.: Centurylong source apportionment of PAHs in Athabasca oil sands re- gion lakes using diagnostic ratios and compound-specific carbon isotope signatures, Environ. Sci. Technol., 47, 6155-6163, 2013

Kelly, E. N., Short, J. W., Schindler, D. W., Hodson, P. V., Ma, M., Kwan, A. K., and Fortin, B. L.: Oil sands development contributes polycyclic aromatic compounds to the Athabasca River and its tributaries, Proc. Natl. Acad. Sci. USA, 106, 2234622351, 2009

Kurek, J., Kirk, J. L., Muir, D. C., Wang, X., Evans, M. S., and Smol, J. P.: Legacy of a half century of Athabasca oil sands development recorded by lake ecosystems, Proc. Natl. Acad. Sci. USA, 110, 1761-1766, 2013.

Ligocki, M. P., Leuenberger, C., and Pankow, J. F.: Trace organic compounds in rain - III. Particle scavenging of neutral organic compounds, Atmos. Environ., 19, 1619-1626, 1985.

Mackay, D., Shiu, W. Y., Ma, K.-C., and Lee, S. C.: Handbook of physical-chemical properties and environmental fate for organic chemicals, Second Ed., CRC Press Taylor \& Francis Group, Boca Raton, Florida, USA, 2006.

Muñoz, B. and Albores, A.: DNA Damage Caused by Polycyclic Aromatic Hydrocarbons: Mechanisms and Markers, Selected Topics in DNA Repair, edited by: Chen, C., InTech, available at: http://www.intechopen.com/books/ (last access:3 February 2915), 2011.

Pankow, J. F.: Common y-intercept and single compound regressions of gas-particle partitioning data vs $1 / \mathrm{T}$, Atmos. Environ. 25, 2229-2239, 1991.

Pankow, J. F.: An absorption model of the gas/aerosol partitioning involved in the formation of secondary organic aerosol, Atmos. Environ., 28, 189-193, 1994.

Parajulee, A. and Wania, F.: Evaluating officially reported polycyclic aromatic hydrocarbon emissions in the Athabasca oil sands region with a multimedia fate model, Proc. Natl. Acad. Sci. USA, 111, 3344-3349, 2014.

Perera, F. P., Li, Z., Whyatt, R., Hoepner, L., Wang, S., Camann, D., and Rauh, V.: Prenatal airborne polycyclic aromatic hydrocarbon exposure and child IQ at age 5 years, Pediatrics, 124, 195-202, 2009.

Poster, D. L. and Baker, J. E.: Influence of submicron particles on hydrophobic organic contaminants in precipitation. 1. Concentrations and distributions of polycyclic aromatic hydrocarbons and polychlorinated biphenyls in rainwater, Environ. Sci. Technol., 30, 341-348, 1995a.

Poster, D. L. and Baker, J. E.: Influence of submicron particles on hydrophobic organic contaminants in precipitation. 2. Scavenging of polycyclic aromatic hydrocarbons by rain, Environ. Sci. Technol., 30, 349-354, 1995b.

Ravindra, K., Sokhi, R., and Van Grieken, R.: Atmospheric polycyclic aromatic hydrocarbons: source attribution, emission factors and regulation, Atmos. Environ., 42, 2895-2921, 2008.

Reid, L., Mackay, D., Celsie, A., and Parnis, M.: Physico-Chemical Properties of Polycyclic Aromatic Compounds and the Polycyclic Aromatic Compound database of properties, Draft report prepared for Environment Canada, 2013.

Rothenberg, S. E., McKee, L., Gilbreath, A., Yee, D., Connor, M., and $\mathrm{Fu}, \mathrm{X}$.: Wet deposition of mercury within the vicinity of a cement plant before and during cement plant maintenance, Atmos. Environ., 44, 1255-1262, 2010. 
Sakata, M. and Asakura, K.: Estimating contribution of precipitation scavenging of atmospheric particulate mercury to mercury wet deposition in Japan, Atmos. Environ., 41, 1669-1680, 2007.

Simcik, M. F.: The importance of surface adsorption on the washout of semivolatile organic compounds by rain, Atmos. Environ., 38, 491-501, 2004.

Škrdlíková, L., Landlová, L., Klánová, J., and Lammel, G.: Wet deposition and scavenging efficiency of gaseous and particulate phase polycyclic aromatic compounds at a central European suburban site, Atmos. Environ., 45, 4305-4312, doi:10.1016/j.atmosenv.2011.04.072, 2011.

Sun, P., Backus, S., Blanchard, P., and Hites, R. A.: Annual variation of polycyclic aromatic hydrocarbon concentrations in precipitation collected near the Great Lakes, Environ. Sci. Technol., 40, 696-701, 2006.

Timoney, K. P. and Lee, P.: Polycyclic aromatic hydrocarbons increase in Athabasca River Delta sediment: Temporal trends and environmental correlates, Environ. Sci. Technol., 45, 4278-4284, 2011.
Wang, X., Zhang, L., and Moran, M. D.: Development of a new semi-empirical parameterization for below-cloud scavenging of size-resolved aerosol particles by both rain and snow, Geosci. Model Dev., 7, 799-819, doi:10.5194/gmd-7-799-2014, 2014.

Wania, F., Mackay, D., and Hoff, J. T.: The importance of snow scavenging of polychlorinated biphenyl and polycyclic aromatic hydrocarbon vapors, Environ. Sci. Technol., 33, 195-197, 1999.

Wickliffe, J., Overton, E., Frickel, S., Howard, J., Wilson, M., Simon, B., Echsner, S., Nguyen, D., Gauthe, D., Blake, D., Miller, C., Elferink, C., Ansari, S., Fernando, H., Trapido, E. and Kane, A.: Evaluation of polycyclic aromatic hydrocarbons using analytical methods, toxicology, and risk assessment research: seafood safety after a petroleum spill as an example. Environ. Health Perspect., 122, 6-9, doi:10.1289/ehp.1306724, 2014.

Zhang, L., Wang, X., Moran, M. D., and Feng, J.: Review and uncertainty assessment of size-resolved scavenging coefficient formulations for below-cloud snow scavenging of atmospheric aerosols, Atmos. Chem. Phys., 13, 10005-10025, doi:10.5194/acp-13-10005-2013, 2013. 